\title{
KAJIAN RENCANA PEMBANGUNAN DOUBLE TRACK PADA EMPLASEMEN STASIUN CILAME (LINTAS CIKAMPEK - PADALARANG)
}

\author{
Ir. Bambang Drajat,MM \\ Dosen STTD \\ J1. Raya Setu no.89 \\ Cibuntu - Cibitung \\ Tlp/Fax : ( 021 ) 8254640
}

\author{
Ir. J.R.C Hosang,MT \\ Dosen STTD \\ J1. Raya Setu no.89 \\ Cibuntu - Cibitung \\ Tlp/Fax : ( 021 ) 8254640
}

\author{
Ir. Tonny C.M Korah,M.Si \\ Dosen STTD \\ J1. Raya Setu no.89 \\ Cibuntu - Cibitung \\ Tlp/Fax : ( 021 ) 8254640
}

\author{
DR. Ir. Djajadi,MM \\ Dosen STTD \\ J1. Raya Setu no.89 \\ Cibuntu - Cibitung \\ Tlp/Fax : ( 021 ) 8254640
}

\author{
Uriansyah P,MM \\ Dosen STTD \\ Jl. Raya Setu no.89 \\ Cibuntu - Cibitung \\ Tlp/Fax : ( 021 ) 8254640
}

\begin{abstract}
Railway transport has many advantages over road transport, among others: mass transport capacity, fast, safe, energy efficient and environmentally friendly and requires relatively little land. For the execution of railway transportation among other elements before the railway operates are elements of infrastructure consisting of railway infrastructure along with railway buildings and railway operation facilities covering signaling, electricity and communications. The infrastructure element is the very vital foundation of rail transport. But the construction of a single track into a double track on the cross is not as easy on the job as is usually done on other crossings because of the contours of hills, ravines and steep slopes.
\end{abstract}

Keyword : Plan, Double Track, Train

\section{ABSTRAKSI}

Transportasi perkeretaapian mempunyai banyak keunggulan dibanding transportasi jalan antara lain: kapasitas angkut besar (massal), cepat, aman, hemat energi dan ramah lingkungan serta membutuhkan lahan yang relatif sedikit. Untuk pelaksanaan angkutan kereta satu diantara unsur lainnya sebelum kereta api beroperasi adalah unsur prasarana yang terdiri dari prasarana jalur berserta bangunan kereta api dan fasilitas operasi kereta api yang melingkupi persinyalan, kelistrikan dan komunikasi. Unsur prasarana merupakan fondasi angkutan kereta api yang sangat vital. Namun pembangunan jalur tunggal menjadi jalur ganda pada lintas tersebut tidak semudah pada pekerjaan seperti biasa dilakukan pada lintas lainnya karena terdapat kontur bukit, jurang dan lereng yang curam.

\section{Kata Kunci : Rencana. Jalur ganda, kereta api}




\section{PENDAHULUAN}

Transportasi perkeretaapian mempunyai banyak keunggulan dibanding transportasi jalan antara lain: kapasitas angkut besar (massal), cepat, aman, hemat energi dan ramah lingkungan serta membutuhkan lahan yang relatif sedikit. Dengan semakin kuatnya isu lingkungan, maka keunggulan kereta api dapat dijadikan sebagai salah satu alasan yang kuat untuk membangun transportasi perkeretaapian sehingga terwujud transportasi yang efektif, efisien dan ramah lingkungan Pembangunan transportasi perkeretaapian nasional diharapkan mampu menjadi tulang punggung angkutan barang dan angkutan penumpang perkotaan sehingga dapat menjadi salah satu penggerak utama perekonomian nasional. Penyelenggaraan transportasi perkeretaapian nasional yang terintegrasi dengan moda transportasi lainnya dapat meningkatkan efisiensi penyelenggaraan perekonomian nasional. Oleh karena itu penyelenggaraan perkeretaapian nasional di masa depan harus mampu menjadi bagian penting dalam struktur perekonomian nasional. Apabila dapat diambil data eksisting kapasitas lintas saat ini yang sesuai dengan Grafik perjalan kereta api antara Jakarta - bandung untuk lintas antara cikampek - padalarang. Keadaan eksisting saat ini untuk jalur ganda baru terbangun antara stasiun cikampek sampai dengan purwakarta, ciganea sampai dengan stasiun sukatani dan stasiun plered sampai dengan stasiun cikadongdong, sehingga antara stasiun cikampek - purwakarta kapasitas kereta api yang dapat lewat sebanyak 155 kereta sampai dengan 201 kereta per hari. Sedangkan untuk stasiun ciganea sampai dengan sukatani sebanyak 155 kereta per hari dan lintas plered sampai dengan cikadongdong juga 155 kereta per hari. Lalu dapat ditelisik kembali untuk petak jalan yang masih dalam keadaan jalur tunggal antara stasiun purwakarta - ciganea kapasitasnya 61 kereta per hari, stasiun sukatani - plered 78 kereta per hari, dan petak cikadongdong - padalarang sebanyak 61 kereta per hari. Dari data eksisting tersebut dapat diketahui perbedaan yang cukup drastic apabila kapasitas lintas suatu jalur yang dalam keadaan jalur tunggal dan jalur ganda. Sehingga apabila dari Jakarta sampai dengan bandung sudah tersambung dengan sistem jalur ganda maka jumlah kereta api yang lewat dapat lebih besar jumlahnya. Namun pembangunan jalur tunggal menjadi jalur ganda pada lintas tersebut tidak semudah pada pekerjaan seperti biasa dilakukan pada lintas lainnya karena terdapat kontur bukit, jurang dan lereng yang curam. Tentunya dibutuhkan teknik yang lebih khusus dalam penanganan tersebut, terlebih lagi tantangan lainnya adalah perihal bangunan stasiun yang sudah ditetapkan sebagai benda cagar budaya, sehingga bangunan tersebut tidak mungkin dihancurkan apabila dilakukan pembangunan stasiun sekaligus pembangunan jalur ganda. Penerapan jalur ganda tersebut sudah tercantum dalam rencana induk perkeretaapian nasional Indonesia $2011-2030$. 


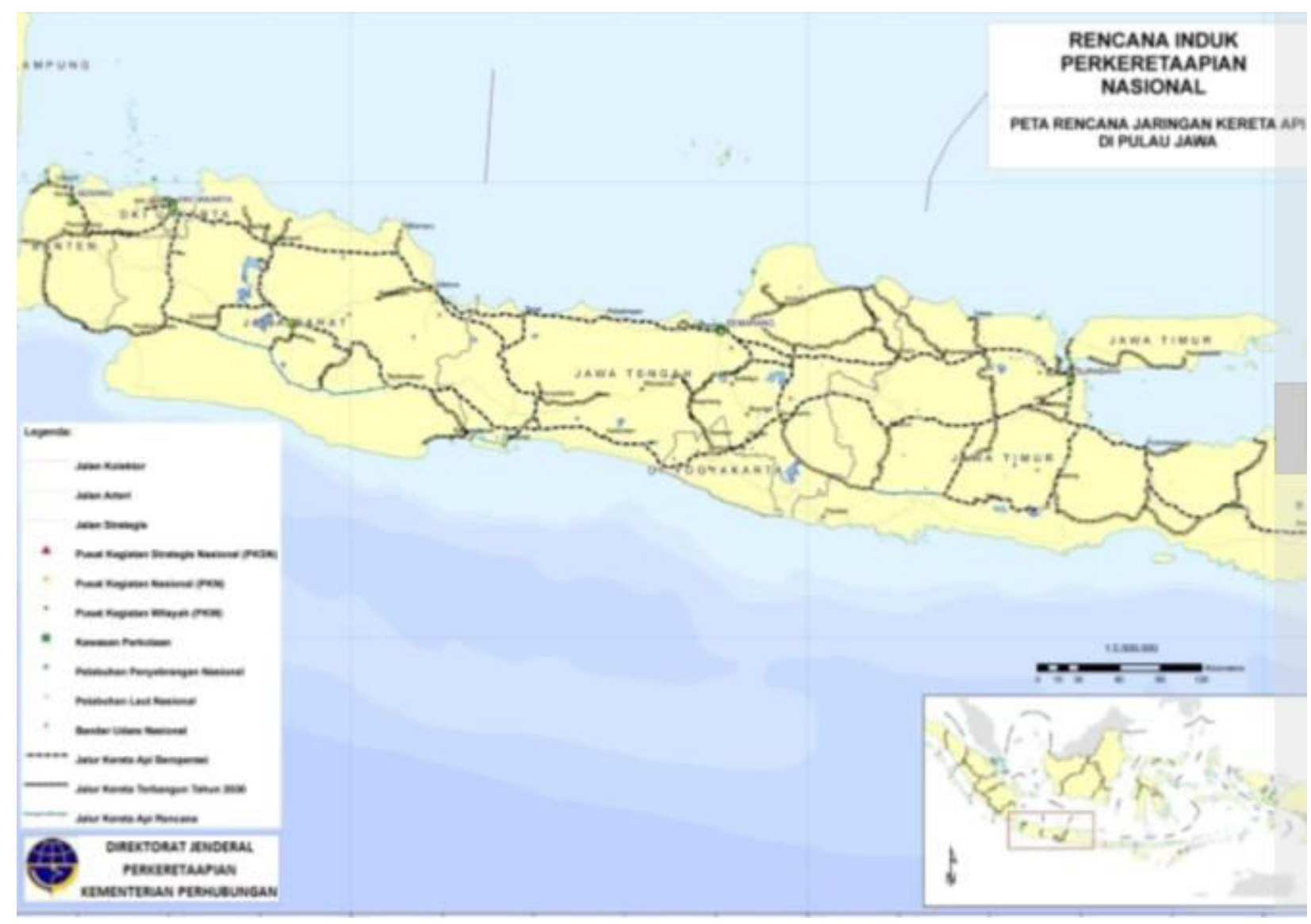

Gambar 2.1.2 Rencana jaringan perkeretaapian terbangun tahun 2030 di pulau jawa

Terkait dengan pembangunan double track di pulau jawa dan pembanguna jaringan perkeretaapian terlihat di gambar 2.2 untuk perencanaan pada tahun 2030 di pulau jawa terbangun jaringan perkeretaapian yang tertera pada gambar., sementara itu dalam target yang telah ditetapkan oleh pemerintah pada Tahap 1 (2011-2016) dan Tahap 2 (2016-2020) untuk lintas padalarang-cicalengka sudah terbangun jaringan listrik aliran atas dimana kereta rel listrik akan beroperasi yang pada implikasinya meningkatkan frekuensi KA pada lintas tersebut, sehinggga jenis-jenis kereta yang merupakan layanan feeder atau kereta api terusan menuju Jakarta dari stasiun padalarang akan meningkat pada lintas padalarang-cikampek.

\begin{tabular}{|c|c|c|}
\hline & Peningkatan Kapasitas Jaringan KA melalui Pembangunan Jalur Ganda dan Elektrifikasi & \\
\hline & - Jalur Ganda dan Elektrifikasi Lintas Serpong - Maja - Rangkasbitung - Merak & \\
\hline & Jalur Ganda dan Elektrifikasi Lintas Manggarai - Jatinegara - Bekasi - Cikarang & \\
\hline & - Jalur Ganda dan Elektrifikasi Lintas Padalarang - Bandung - Cicalengka & \\
\hline & - Elektrifikasi Lintas Kutoarjo - Yogyakarta - Solo & E \\
\hline & - Jalur Ganda dan Elektrifikasi Lintas Duri - Tangerang & \\
\hline
\end{tabular}

Tabel 2.1.3 Rencana Pengembangan pada lintas antara Padalarang - Cicalengka

Tentunya dalam melaksanakan pekerjaan pembangunan prasarana jalan rel harus memperhatikan standar-standar teknis yang berlaku, dalam hal ini Pemerintah melalui Kementerian Perhubungan menetapkan Peraturan Menteri Perhubungan Nomor 60 Tahun 2012 tentang persyaratan teknis jalur kereta api. Dalam persyaratan teknis jalur kereta api meliputi: persyaratan teknis untuk jalan rel dengan lebar jalur $1067 \mathrm{~mm}$ dan untuk $1435 \mathrm{~mm}$. namun karena jalur pada emplasemen stasiun Cilame adalah $1067 \mathrm{~mm}$, maka pembahasan focus pada teknis lebar jalur $1067 \mathrm{~mm}$. Dalam persyaratan teknis jalur kereta api yang dimaksud dengan persyaratan teknis jalur kereta api adalah 

a. Jalan rel
b. Jembatan, dan
c. Terowongan

Secara teknis diartikan konstruksi jalur kereta api tersebut harus aman dilalui oleh sarana perkeretaapian dengan tingkat kenyamanan tertentu selama umur konstruksinya.

\subsection{Kelas jalan rel dan jenis rel}

\begin{tabular}{|c|c|c|c|c|c|c|c|c|}
\hline \multirow{2}{*}{$\begin{array}{l}\text { Kelas } \\
\text { Jalan }\end{array}$} & \multirow{2}{*}{$\begin{array}{c}\text { Daya Angkut } \\
\text { Lintas } \\
\text { (ton/tahun) }\end{array}$} & \multirow{2}{*}{$\underset{\substack{\text { maks } \\
(\mathrm{km} / \mathrm{jam})}}{\mathrm{V}}$} & \multirow{2}{*}{$\begin{array}{c}\text { P } \\
\text { maks } \\
\text { gandar } \\
\text { (ton) }\end{array}$} & \multirow{2}{*}{ Tipe Rel } & Jenis Bantalan & \multirow{2}{*}{$\begin{array}{c}\text { Jenis } \\
\text { Penambat }\end{array}$} & \multirow{2}{*}{$\begin{array}{l}\text { Tebal } \\
\text { Balas } \\
\text { Atas } \\
\text { (cm) }\end{array}$} & \multirow{2}{*}{$\begin{array}{l}\text { Lebai } \\
\text { Baht } \\
\text { Balas } \\
\text { (cm) }\end{array}$} \\
\hline & & & & & $\begin{array}{l}\text { Jarak antar sumbu } \\
\text { bantalan }(\mathrm{cm})\end{array}$ & & & \\
\hline \multirow{2}{*}{1} & \multirow{2}{*}{$>20.10^{6}$} & \multirow{2}{*}{120} & \multirow{2}{*}{18} & \multirow{2}{*}{ R.60/R.54 } & Beton & \multirow{2}{*}{$\begin{array}{l}\text { Elastis } \\
\text { Ganda }\end{array}$} & \multirow{2}{*}{30} & \multirow{2}{*}{60} \\
\hline & & & & & 60 & & & \\
\hline \multirow{2}{*}{ ॥ } & \multirow{2}{*}{$\begin{array}{c}10.10^{6}- \\
20.10^{6}\end{array}$} & \multirow{2}{*}{110} & \multirow{2}{*}{18} & \multirow{2}{*}{ R.54/R.50 } & Beton/Kayu & \multirow{2}{*}{$\begin{array}{l}\text { Elastis } \\
\text { Ganda }\end{array}$} & \multirow{2}{*}{30} & \multirow{2}{*}{50} \\
\hline & & & & & 60 & & & \\
\hline \multirow{2}{*}{ III } & \multirow{2}{*}{$5.10^{6}-10.10^{6}$} & \multirow{2}{*}{100} & \multirow{2}{*}{18} & \multirow{2}{*}{ R.54/R.50/R.42 } & Beton/Kayu/Baja & \multirow{2}{*}{$\begin{array}{l}\text { Elastis } \\
\text { Ganda }\end{array}$} & \multirow{2}{*}{30} & \multirow{2}{*}{40} \\
\hline & & & & & 60 & & & \\
\hline \multirow{2}{*}{ N } & \multirow{2}{*}{$\begin{array}{c}2,5.10^{\circ}- \\
5.10^{6}\end{array}$} & \multirow{2}{*}{90} & \multirow{2}{*}{18} & \multirow{2}{*}{ R.54/R.50/R.42 } & Beton/Kayu/Baja & \multirow{2}{*}{$\begin{array}{l}\text { Elastis } \\
\text { Ganda/ } \\
\text { Tunggal }\end{array}$} & \multirow{2}{*}{25} & \\
\hline & & & & & 60 & & & 40 \\
\hline v & $<25.10^{\circ}$ & 80 & 18 & $R 42$ & Kayu/Baja & Elastis & 25 & 35 \\
\hline & & & & & 60 & Tunggal & 20 & 35 \\
\hline
\end{tabular}

Tabel 2.2.1 Kelas jalan Rel untuk lebar jalur 1067mm

Kelas jalan rel berkaitan dengan beban lalu lintas atau passing tonnage yaitu beban lintas yang ditanggung oleh jalan rel tersebut dalam kurun waktu 1 tahun.Rel adalah komponen yang memikul beban langsung dari roda kereta api, pentingnya komponen ini artinya merupakan tumpuan paling kritis. Dengan besarnya beban yang diterima oleh rel maka rel mimiliki kriteria-kriteria yang harus terpenuhi sebagai berikut:

- Minimum perpanjangan (elongation) $10 \%$

- Kekuatan Tarik (tensile strength) minimum $1175 \mathrm{~N} / \mathrm{mm}^{2}$

- Tingkat kekerasan rel tidak boleh kurang dari 320 BHN

Terkait ke-3 gambar diatas berikut adalah tabel ukuran dimensi penampang rel berdasarkan bagian-bagiannya :

\begin{tabular}{|c|c|c|c|c|}
\hline \multirow{2}{*}{$\begin{array}{c}\text { Besaran } \\
\text { Geometri Rel }\end{array}$} & \multicolumn{4}{|c|}{ Tipe Rel } \\
\hline & R 42 & R 50 & R 54 & R 60 \\
\hline$H(\mathrm{~mm})$ & 138,00 & 153,00 & 159,00 & 172,00 \\
\hline$B(\mathrm{~mm})$ & 110,00 & 127,00 & 140,00 & 150,00 \\
\hline $\mathrm{C}(\mathrm{mm})$ & 68,50 & 65,00 & 70,00 & 74,30 \\
\hline $\mathrm{D}(\mathrm{mm})$ & 13,50 & 15,00 & 16,00 & 16,50 \\
\hline$E(\mathrm{~mm})$ & 40.50 & 49,00 & 49,40 & 51,00 \\
\hline $\mathrm{F}(\mathrm{mm})$ & 23,50 & 30,00 & 30,20 & 31,50 \\
\hline $\mathrm{G}(\mathrm{mm})$ & 72,00 & 76,00 & 74,79 & 80,95 \\
\hline $\mathrm{R}(\mathrm{mm})$ & 320,00 & 500,00 & 508,00 & 120,00 \\
\hline $\mathrm{A}\left(\mathrm{cm}^{2}\right)$ & 54.26 & 64,20 & 69,34 & 76,86 \\
\hline$W(\mathrm{~kg} / \mathrm{m})$ & 42,59 & 50,40 & 54,43 & 60,34 \\
\hline I. $\left(\mathrm{cm}^{4}\right)$ & 1369 & 1960 & 2346 & 3055 \\
\hline$Y_{b}(\mathrm{~mm})$ & 68,50 & 71,60 & 76,20 & 80,95 \\
\hline A & \multicolumn{4}{|l|}{ luas penampang } \\
\hline W & \multicolumn{4}{|c|}{ berat rel permeter } \\
\hline Ix & \multicolumn{4}{|c|}{ momen inersia terhadap sumbu $x$} \\
\hline$Y_{b}$ & \multicolumn{4}{|c|}{ jarak tepi bawah rel ke garis netral } \\
\hline
\end{tabular}




\section{METODOLOGI PENELITIAN}

Adapun tahapan-tahapan rencana penelitian ini adalah sebagai berikut :

1. Menetapkan maksud dan tujuan dilakukannya penelitian serta menentukan ruang lingkup dan batasan-batasan permasalahan dari penelitian yang dilakukan.

2. Mengumpulkan data-data yang diperlukan serta mendukung penelitian yang dilakukan baik data sekunder maupun data primer.

3. Mengidentifikasi permasalahan pada sistem manajemen perawatan alat peringatan dini perlintasan sebidang.

\subsection{BAGAN ALIR PENELITIAN}

Untuk mempermudah dalam proses penelitian, penulis menyajikan bagan alir yang merupakan tahapan dan urutan proses sebagai berikut :

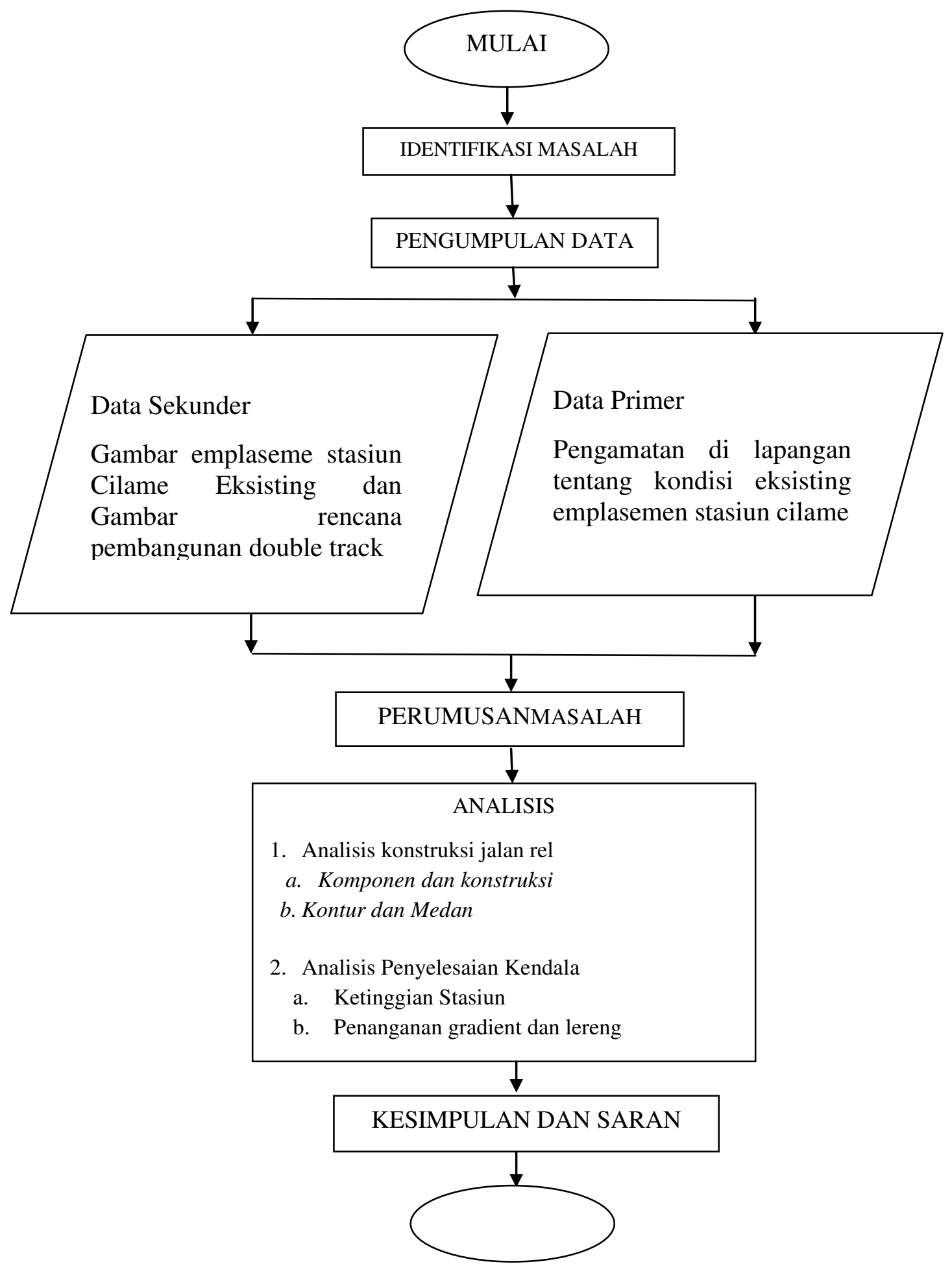




\section{OBJEK PENELITIAN}

Tempat yang menjadi objek penelitian ini adalah emplasemen stasiun cilame dan wilayah jembatan BH537 pada lintas Cikampek - Padalarang.

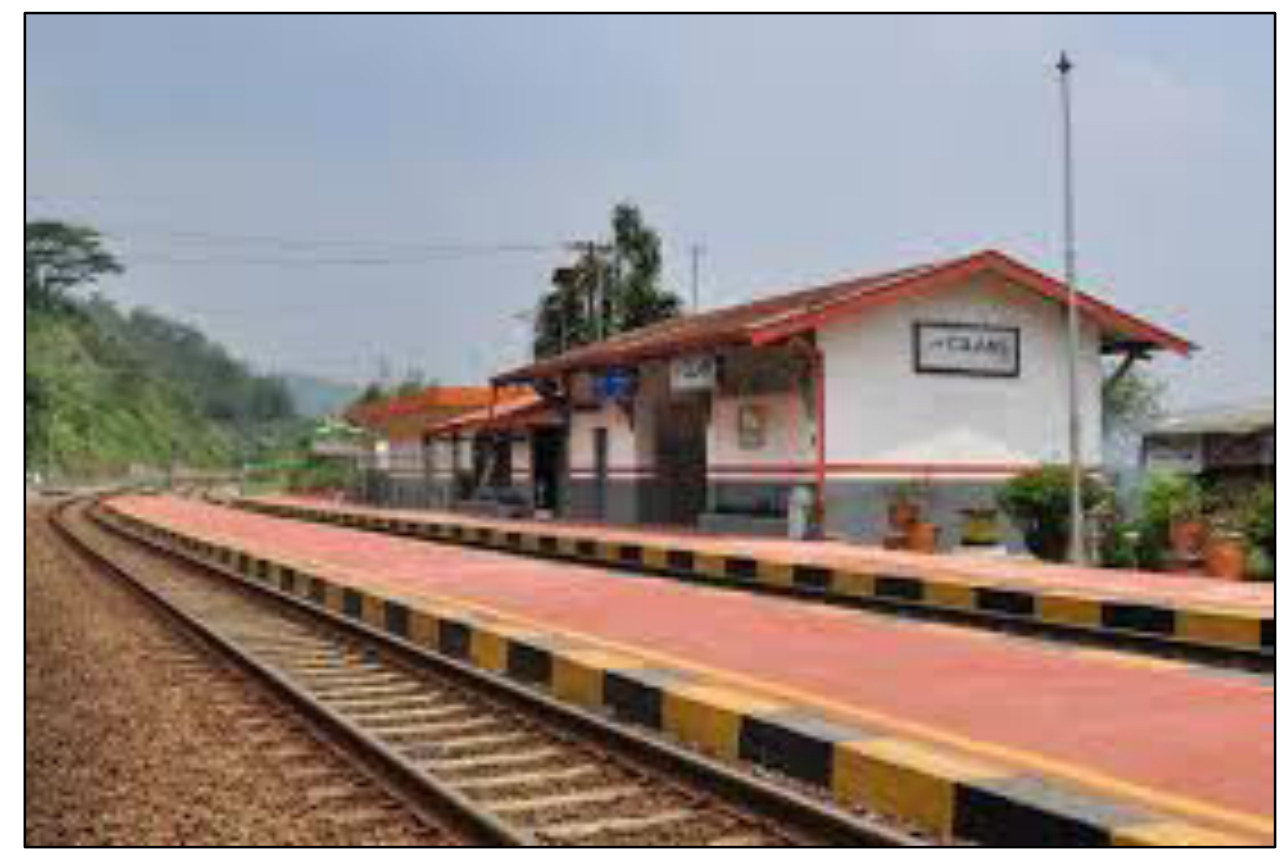

Gambar 3.3.1 Stasiun Cilame

\section{METODOLOGI PENELITIAN}

1. Sumber Data

Dalam pengumpulan data, dikenal dua jenis data yaitu data sekunder dan data primer. Kedua data inilah yang akan menjadi dasar penelitian untuk memperoleh jawaban dari pemecahan masalah yang telah dikemukakan sebelumnya. Berikut merupakan penjabaran dari data primer dan data sekunder, antara lain :

a. Data Sekunder

Dalam pengumpulan data sekunder, didapatkan dari instansi-instansi terkait, dalam hal ini yaitu dari Direktorat Prasarana Perkeretaapian, Ditjen KA dan Balai Teknik Perkeretaapian Wilayah Jawa bagia Barat, Ditjen KA. Data yang didapat yaitu gambar teknis rencana pembangunan double track pada emplasemen stasiun Cilame.

b. Data Primer

Data primer adalah data yang didapat melalui pengamatan secara langsung di lapangan melalui pelaksanaan survey. Data primer penelitian ini hanya pengamatan langsung di lapangan, terhadap kondisi eksisting stasiun cilame dan berkonsultasi langsungdengantenaga ahli pembangunan jalan rel di lapangan dan dengan pejabat instansi terkait (Direktorat Prasarana dan Balai Teknik Perkeretaapian, Ditjen KA).

2. Tahap Penelitian
a. Tahap I
Yaitu melakukan identifikasi masalah.
b. Tahap II 
Yaitu tahap persiapan pengumpulan data, menyiapkan alat-alat yang diperlukan untuk pengumpulan data.

c. Tahap II

Yaitu tahap pengumpulan data dengan melakukan survei-survei yang diperlukan untuk memperoleh data seakurat mungkin.

d. Tahap IV

Yaitu melakukan analisa data-data yang telah diperoleh.

e. Tahap V

Memberikan kesimpulan dan usulan untuk pemecahan masalah.

\section{KONDISI YANG DIHARAPKAN}

Pelaksanaan pembangunan double track di stasiun Cilame diharapkan dapat meningkatkan kualitas pelayanan ,selain itu juga mempermudah akses warga dengan adanya pembangunan terowongan underpass baru sehingga meningkatkan keselamatan pengguna jalan raya. Pada keadaan ke depannya stasiun cilame akan memilki 3 jalur aktif untuk operasi dan 1 jalur untuk jalur tangkap, dari posisi sebelumnya yang memiliki 2 jalur aktif untuk operasi dan 1 jalur untuk jalur tangkap. Keadaan peron stasiun juga akan ditinggikan sesuai standar yaitu setinggi 1 meter dari kop rel. sedangkan posisi jembatan BH 537 kelandaiannya akan dibuat tidak terlampau curam dan posisi dari stasiun eksisting yang merupakan stasiun dengan status cagar budaya sehingga tidak dapat dilakukan pembongkaran terhadap stasiun tersebut. Kemudian posisi dari stasiun eksisting ke stasiun baru selisih ketinggiannya dibuat tidak terlampau tinggi sehingga memudahkan akses penumpang keluar dan masuk stasiun.

\section{ANALISA}

\subsection{Kondisi Eksistig Stasiun Cilame}

\begin{tabular}{|c|c|c|c|c|c|}
\hline \multirow{2}{*}{ No. } & \multirow{2}{*}{ Nama } & \multirow{2}{*}{ Lintang (U) } & \multirow{2}{*}{ Bujur (T) } & \multicolumn{2}{|c|}{$\begin{array}{c}\text { PerlintasanSebidan } \\
\text { g }\end{array}$} \\
\hline & & & & $\begin{array}{c}\text { LebarJa } \\
\text { lan }(\mathbf{m})\end{array}$ & $\begin{array}{c}\text { KelasJal } \\
\text { an }\end{array}$ \\
\hline 1 & As; PPKA R. Dalam & $6^{\circ} 51^{\prime} 12.99^{\prime \prime}$ & $107^{\circ} 40^{\prime} 31^{\prime \prime}$ & & \\
\hline 2 & SinyalmasukSasaksaat & $6^{\circ} 51^{\prime} 19^{\prime \prime}$ & $\begin{array}{c}107^{\circ} 40 ' 32.99 \\
n\end{array}$ & & \\
\hline 3 & $\begin{array}{c}\text { As; jalurrelsegaris PPKA } \\
\text { Reldidepan Kantor }\end{array}$ & $6^{\circ} 51^{\prime} 18^{\prime \prime}$ & $\begin{array}{c}107^{\circ} 40^{\prime} 32.99 \\
" \prime\end{array}$ & & \\
\hline 4 & SinyalmasukPadalarang & $6^{\circ} 49^{\prime} 32.99^{\prime \prime}$ & $107^{\circ} 35^{\prime} 21^{\prime \prime}$ & & \\
\hline 5 & $\begin{array}{c}\text { Pintuperlintasansebidangterdek } \\
\text { at }\end{array}$ & $6^{\circ} 51 ' 14^{\prime \prime}$ & $107^{\circ} 40^{\prime} 8^{\prime \prime}$ & 8 & III \\
\hline 6 & Peta & $6^{\circ} 48^{\prime} 12.11^{\prime \prime}$ & $\begin{array}{c}107^{\circ} 27^{\prime} 48.26 \\
\text { " }\end{array}$ & & \\
\hline
\end{tabular}




\section{Layout Emplasemen}

\section{CILAME}
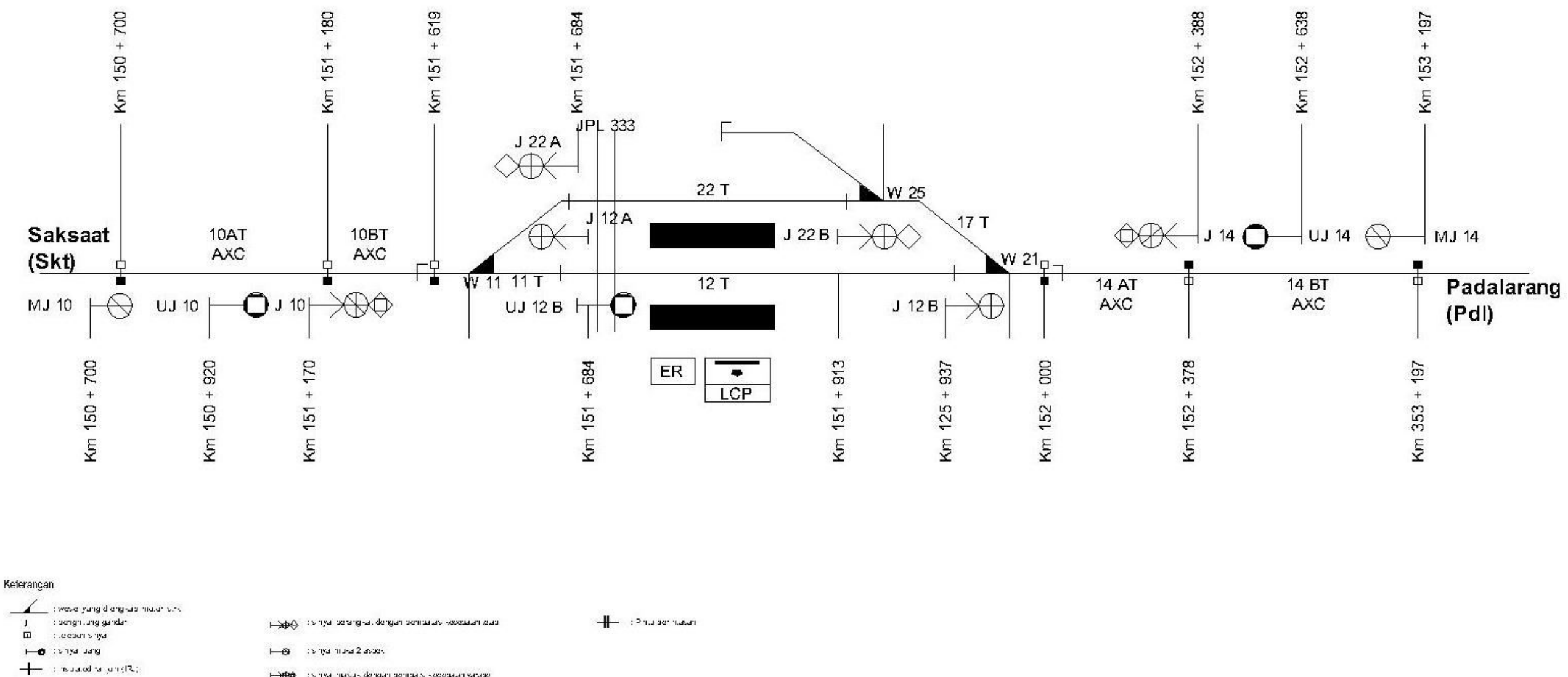

\#- : Р.

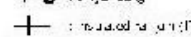


Jalur

Panjang

Nomor Jenis $\begin{array}{cccccc} & \text { Total Freepal Efektif } & \text { KapasitasRel } & \text { Rel } & \text { an }\end{array}$

(m) $\quad$ l (m) (m)

$(\mathbf{k m} / \mathbf{j})$

\begin{tabular}{|l|l|l|l|l|l|l|l|l|}
\hline 1 & I & Utama & 355 & 704 & 327 & $\begin{array}{c}1 \text { loko + 14 } \\
\text { kereta }\end{array}$ & R54 & 55 \\
\hline 2 & II & Siding & 325 & 704 & 303 & $\begin{array}{c}\text { 1 loko + 13 } \\
\text { kereta }\end{array}$ & R54 & 55 \\
\hline
\end{tabular}

Peron

\begin{tabular}{|c|c|c|c|c|c|c|c|}
\hline No & Nomor & Posisi & $\begin{array}{c}\text { Panjan } \\
\text { g (m) }\end{array}$ & $\begin{array}{c}\text { Lebar } \\
\text { (m) }\end{array}$ & $\begin{array}{c}\text { Tinggi } \\
\text { (cm) }\end{array}$ & JenisPerkerasan & $\begin{array}{l}\text { Jenis } \\
\text { Peron }\end{array}$ \\
\hline 1 & I & PPKA - Jalur I & 80.7 & 3 & 15 & Semen & Rendah \\
\hline 2 & II & Jalur I - Jalur II & 80.7 & 3.1 & 15 & Semen & Rendah \\
\hline
\end{tabular}

Overcapping

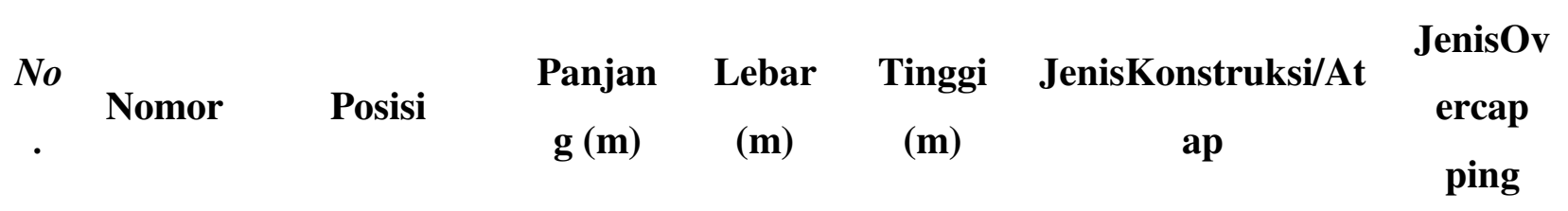

Sinyal

No Nama Kode Posisi KM Jalur Jenis

\begin{tabular}{|c|c|c|c|c|c|c|}
\hline 1 & Muka & MJ1210 & $150+700$ & I & Elektrik & Elektrik VPI \\
\hline 2 & Ulang & UJ1210 & $150+920$ & I & Elektrik & Elektrik VPI \\
\hline 3 & Masuk & J1210 & $151+170$ & I & Elektrik & Elektrik VPI \\
\hline
\end{tabular}




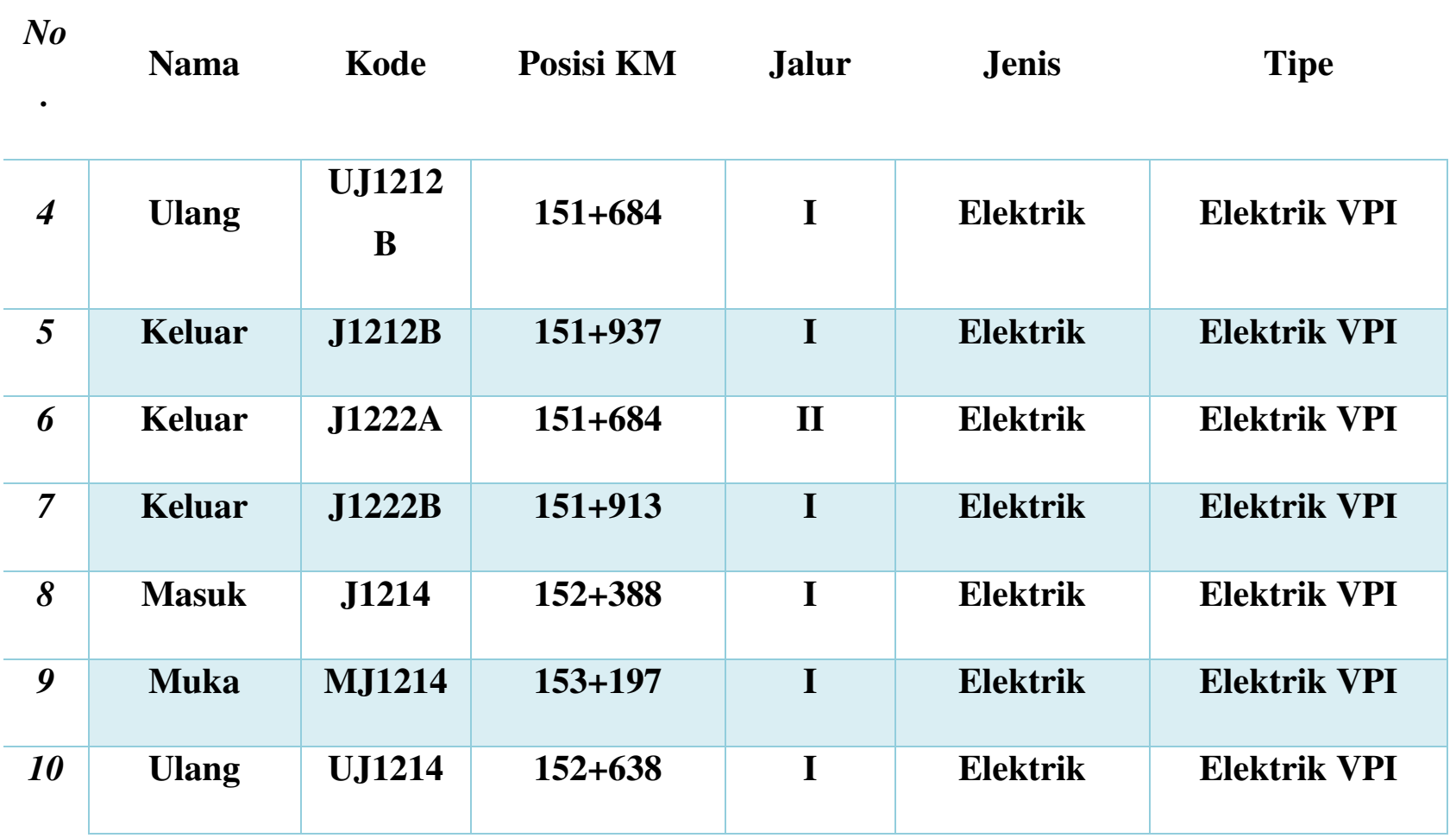

$$
\text { Wesel }
$$

\begin{tabular}{|c|c|c|c|c|c|c|} 
No & Kode & Posisi KM & Jenis & Sudut & Tipe & JenisTerlayan \\
\hline$\cdot$ & W1211 & $151+630$ & Elektrik & $1: 10$ & R33 & Terpusat \\
\hline 2 & W1225 & $151+955$ & Elektrik & $1: 10$ & R33 & Terpusat \\
\hline 3 & W1217 & $151+985$ & Elektrik & $1: 10$ & R33 & Terpusat \\
\hline
\end{tabular}

\section{LAA}

$\begin{array}{ccccccc}\text { No } & \text { Luasan } & & \text { KapasitasG } & \text { Kilometer } & \text { Kapasitas } \\ & \text { GarduT } & \text { Lokasi } & \text { TiangListrikA } & \text { Luasan ER } & \text { ER } \\ & \text { raksi } & & \text { arduTraksi } & \text { liranAtas } & & \text {. }\end{array}$




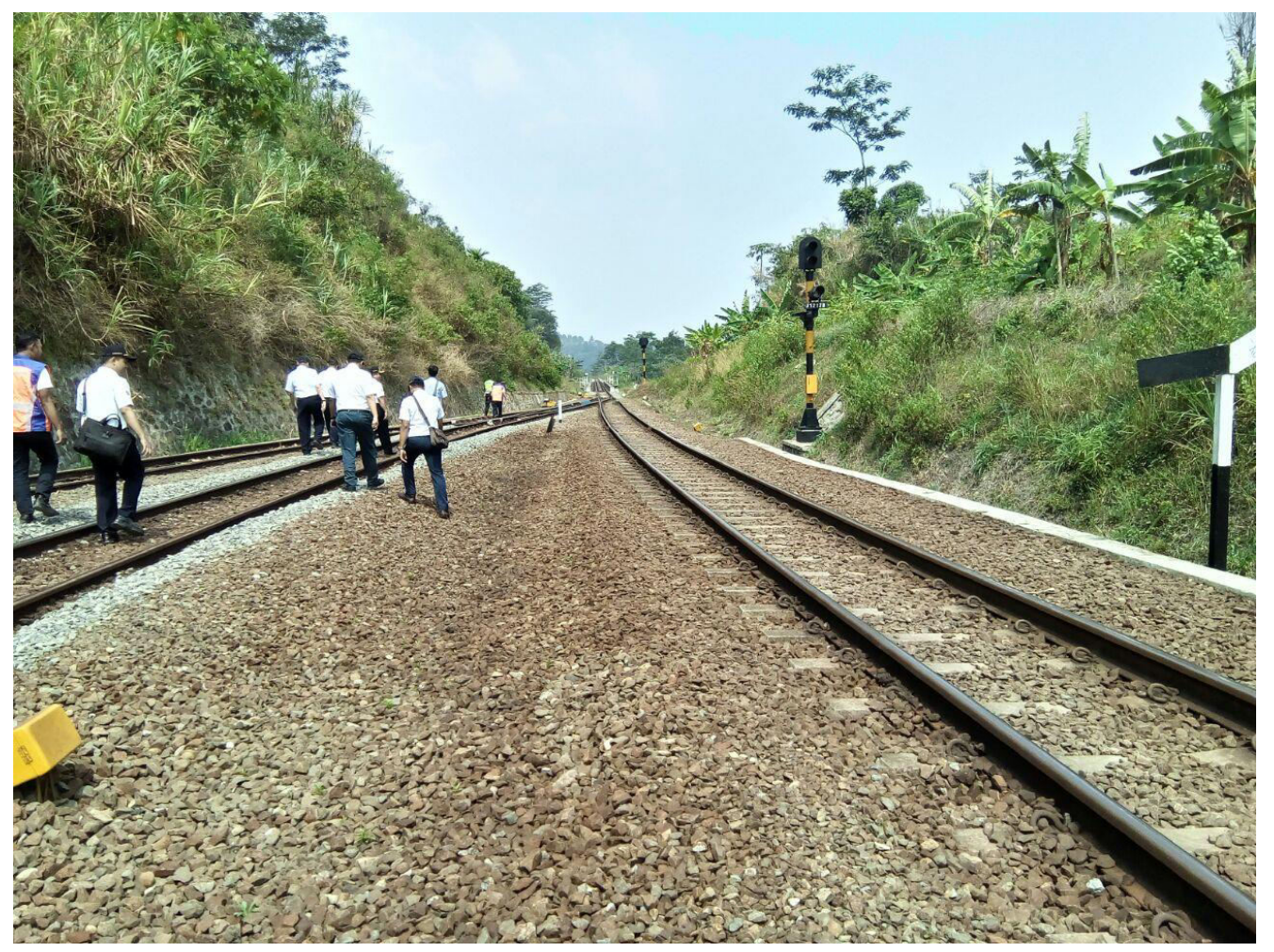

Gambar 4.6 Survei kea rah jembatannomor BH 537

\section{KESIMPULAN DAN SARAN}

Kesimpulan

Berdasarkan materi dan data yang terkumpul dan hasil dari diskusi, penelaahan dan pengkajian atas data sekunder dan primer didapatkan kesimpulan sebagai berikut :

1. Pembangunan double track pada stasiun cilame dilakukan dengan penanganan ekstra karena melakukan peninggian level stasiun dan menggeser posisi rel dari posisi eksisting sehingga pada rencana awal perbedaan ketinggian dapat mencapai 4 meter antara stasiun baru dan stasiun stasiun lama, kemudian dilakukan penuruan level perbedaan menjadi 1 meter dengan tujuan tidak membuat gradient antara stasiun cilame-sasaksaat menjadi lebih curam dan hal yang sama untuk gradient antara stasiun cilame-padalarang, khususnya mengurangi sudut gradient pada titik pertemuan tanah emplasemen cilame dengan pangkal jembatan no BH 537

2. Penanganan lereng pada rencana emplasemen stasiun yang baru dan pembangunan jembatan BH 357 yang baru, dilakukan dengan penanganan metode selubung beton yang ditancapkan ke lereng. 
Saran

Pada proses pembangunan double track kedepannya, perlu disarankan memerhatikan dan memenuhi peraturan serta kriteria yang telah ditetapkan oleh pemerintah seperti Undang-Undang Nomor 23 Tentang Perkeretaapian, Peraturan Pemerintah nomor 56 tahun 2009 tentang penyelenggaraan perkeretaapian dan Peraturan Menteri Perhubungan yang terkait seperti Peraturan Menteri Perhubungan nomor 60 Tahun 2012 tentang standar teknis jalan rel, Peraturan Menteri Perhubungan nomor 189 Tahun 2015 Tentang standar Pelayanan minimum pada stasiun Kereta api dan Peraturan Menteri Perhubungan Nomor 24 Tahun 2015 tentang standar keselamatan Kereta api

\section{DAFTAR PUSTAKA}

, Undang-Undang Republik Indonesia No. 23 Tahun 2007 Tentang Perkeretaapian

, Peraturan Pemerintah Republik Indonesia nomor 56 Tahun 2009 Tentang Penyelenggaraan Perkeretaapian

, Peraturan Pemerintah Republik Indonesia nomor 72 Tahun 2009 Tentang Lalu Lintas Kereta api

, Peraturan Pemerintah Republik Indonesia nomor 47 Tahun 2014 Tentang standar pelayanan minimum untuk angkutan orang dengan kereta api 
